\title{
GLAD!
}

Revue sur le langage, le genre, les sexualités

$06 \mid 2019$

Varia

\section{Roselyne et Roselon}

Roselyne and Roselon

Julie Sorel

\section{(2) OpenEdition}

Journals

Édition électronique

URL : http://journals.openedition.org/glad/1584

DOI : $10.4000 /$ glad. 1584

ISSN : 2551-0819

Éditeur

Association GSL

\section{Référence électronique}

Julie Sorel, « Roselyne et Roselon », GLAD! [En ligne], 06 | 2019, mis en ligne le 01 juillet 2019, consulté le 17 décembre 2020. URL : http://journals.openedition.org/glad/1584 ; DOI : https://doi.org/10.4000/ glad. 1584

Ce document a été généré automatiquement le 17 décembre 2020.

\section{(c) (i) (9)}

La revue GLAD! est mise à disposition selon les termes de la Licence Creative Commons Attribution Pas d'Utilisation Commerciale - Pas de Modification 4.0 International. 


\title{
Roselyne et Roselon
}

\author{
Roselyne and Roselon
}

\author{
Julie Sorel
}
Ce média ne peut être affiché ici. Veuillez vous reporter à l'édition en ligne http:// journals.openedition.org/glad/1584

2 Les hommes et les femmes d'ici, qui s'affolent quand il pleut, ont chacune et chacun un secret à garder. «El secreto » qu'elleux disent. Chacune et chacun croient leur secret unique. Et parfois c'est l'inverse, toutes et tous pensent avoir le même secret qu'il ne faut pas divulguer. Car les hommes et les femmes d'ici sont changeantes dans leur comportement.

3 Ce qui embrouille encore les choses c'est que le changement n'arrive pas pour tout le monde au même moment. Par exemple le secret de madame Curjaz c'est son nom. Tout le monde pense que son mari s'appelle Jaz et elle Cur ou bien l'inverse. Mais tout le monde a tort. Madame et monsieur Curjaz ont un secret en commun.

4 Quand elle et lui se sont rencontrées, les deux avaient un secret. Elle et lui ne savaient pas que leur secret se ressemblait. Tant qu'elle et lui s'appelaient par leur prénom tout allait bien. Elle s'appelait Roselyne, il s'appelait Roselon. C'était mignon.

5 Un jour il voulut lui écrire mais il n'osait pas lui demander son nom car il devrait donner le sien en retour et il en avait honte. Il ne savait pas où elle habitait et elle n'était jamais allée chez lui non plus. Chacun•e cachait son identité comme un secret car elle aussi avait honte de son nom.

6 Mais les deux s'aimaient vraiment beaucoup et l'envie leur prenait souvent de se lier pour la vie. Quand elle lui prenait la main et l'entraînait en forêt, ça leur faisait comme des papillons dans tout le corps. Mais Roselyne et Roselon se sentaient chenille et n'osaient pas le dire à l'autre.

7 Un jour, elle ou lui, on ne sait pas qui - c'est leur secret - décida d'en parler, de la chenille et des papillons.

Et les deux se comprirent instantanément. 
Allait-il, allait-elle continuer avec le dévoilement du nom ?...

Il me faut expliquer le contexte. À la fin du siècle dernier, l'ancienne loi qui, en France, donnait aux enfants le nom de leur père pour rendre publique l'intimité de la conception, devint obsolète quand l'insémination artificielle fut possible et permise à partir d'un donneur anonyme. Un nouveau décret fut promulgué qui permettait aux couples mariés de donner à leurs enfants le nom qu'ils voudraient, celui de la mère ou celui du père pourvu que ce soit le même pour tous les enfants nés des mêmes parents, on dira plus simplement de la même famille, que le père soit le géniteur ou non.

La coutume qui donnait aux mères le nom des pères résista un certain temps, et d'autant plus qu'elle commençait avant même que les femmes deviennent mère, c'està-dire dès le mariage, dont le but était de rendre officielles les coucheries, desquelles résulterait une naissance.

Quand le mariage homosexuel devint légal, il fallut trouver une nouvelle façon de nommer les deux entités d'un amour commun, pour le cas où il y aurait des enfants à la clé, que ce soit par adoption ou insémination. Certes la possibilité existait aussi d'ajouter les deux noms pour en faire un seul. Mais, à la génération suivante, on ne pouvait pas continuer ainsi car les enfants auraient quatre noms, la génération suivante huit et la prochaine seize et de tant prendre d'importance les noms allaient devenir des pages entières qui feraient oublier ce que l'on avait à dire.

Il fut donc convenu d'aller dans le sens inverse, celui du raccourcissement. Chacun des parents donnerait une syllabe à son enfant.

C'est à ce moment-là que Roselyne et Roselon se rencontrèrent.

Et puisque l'une et l'autre avaient honte de leur nom, leur amour commun permettrait d'en changer se disait-elle de son côté et se disait-il du sien.

"Je te dévoilerai mon nom de chenille, dit Roselyne à Roselon, si tu me dévoiles le tien aussi ».

Et Roselon fut d'accord. C'est ainsi qu'il apprit qu'elle s'appelait Roselyne Pète. La déception fut grande pour Roselon, car son nom de chenille à lui ne changerait pas grand-chose pour devenir papillon. Quand Roselyne le vit triste, elle eut peur de comprendre. Et pour ne pas prolonger leur tourment, ou bien le partager, elle lui somma de dire vite son nom.

«Hélas ! fit-il, je m'appelle Roselon Péton. »

Qu'on le tourne dans tous les sens leur nom de papillon ne pouvait pas être très différent de leur nom de chenille. Si l'on prenait les deux premières syllabes, ça faisait Pètpèt, Pépé ou Pépèt. Pètpèt ça redoublait le problème. Pépé, ça les vieillissait tout de suite.

20 Pépèt ça les faisait croire riches, ou avares, ou dépensier et dépensière et ni Roselyne ni Roselon ne souhaitaient qu'on pense à l'argent en les voyant ou en parlant d'ellui.

Si l'on prenait les deux dernières syllabes, ça faisait Téton ou Tonte. Téton ça renvoyait encore à un endroit du corps même si pas le même et Tonte réveillait de mauvais souvenirs dans l'histoire avec un grand $\mathrm{H}$ que Roselyne et Roselon auraient souhaité hacher à coups de machette pour ne plus vivre d'horreurs guerrières.

Si l'on prenait la première syllabe de l'un et la deuxième syllabe de l'autre ça faisait Tonpèt ou Pèton. Aucune perspective de changement ! 
L'oiseau qui s'était posé sur l'épaule de l'enfant d'avant avait tout entendu de leur conversation et des pensées qui l'accompagnaient.

Il vint les rejoindre dans la forêt et se mit à gazouiller et gazouiller si fort que Roselyne et Roselon se regardèrent étonné'es et décidèrent de l'écouter.

Dans le gazouillis de l'oiseau, chacune et chacun entendaient ce qu'ellil voulait.

Roselyne entendit un conseil. Roselon entendait une chanson. Mais les deux disaient pareil.

Dans le texte ça donnait :

Changer pour changer, Changez tout! Changer pour changer, changez tout!

C'était dit sur tous les tons, en vocalises ou en gazouillis, en murmure ou en sifflet, mais aucun doute ne pouvait subsister, c'était bien un conseil que l'oiseau leur donnait.

Alors Roselyne et Roselon optèrent pour la solution du changement radical. Leur nom commun n'aurait que deux syllabes mais aucune des deux ne rappellerait leurs anciens sons. Et c'est ainsi que Roselyne devint Madame Curjaz et Roselon Monsieur Curjaz aussi.

Pourquoi Curjaz? Parce que Cur veut dire pourquoi en latin et jaz à cause de la musique de l'oiseau.

Mais tout ceci est un secret qu'il ne faut surtout pas répéter.

\section{INDEX}

Thèmes: Créations

Mots-clés : elleux, chacun•e [JakÆn], ellui, ellil, nom de famille

Keywords : they, each one, her im, she, surname

\section{AUTEUR}

\section{JULIE SOREL}

Julie Sorel : demi-sœur de Julien Sorel. Issue d'un mariage secret, tardif et posthume entre Stendhal et Agatha Christie. A vécu dans la clandestinité depuis sa naissance. Le Roman d'Anna est son œuvre unique. Les passages cités sont des extraits du premier tome : Le Manuscrit secret. 